\title{
Data of risk analysis management in university campuses
}

\author{
Alireza Dehdashti ${ }^{1}$, Farin Fatemi ${ }^{*}$, Muhammadreza Janati ${ }^{2}$, Fatemeh Asadi ${ }^{2}$ and Marzieh Belji Kangarloo ${ }^{2}$
}

\begin{abstract}
Objectives: This data paper aims to provide the data set of a practical method to health, safety, and environmental risk assessment to assess and rank potential threats/hazards and to prevent and decrease the accidents and harmful consequences at an academic setting. Descriptive data on type of hazards, places, and persons at risk were collected. Quantitative data on risk probability and severity of identified hazards were determined. Additionally, the descriptive statistics and analytical tests were applied to create a concise perspective on health, safety and environmental hazards/threats situation in research location under study. The dataset further provides information on the prioritization of determined risks according to the relevant scores and levels for doing the relevant control measures to remove and mitigate the related risks.

Data description: This paper provides data of comprehensive risk assessment of health, safety and, environmental hazards of academic setting. For each identified hazard, the descriptive and numeric data are available. The information about the risk level and prevention or mitigation measure related to each hazard is provided. Additionally, the statistical tests are applied for determining the relations among the variables under study. The data and methodology on risk assessment in this article may be used to manage variety of risks in higher education institutions.
\end{abstract}

Keywords: Hazards, Risk assessment, Academic settings

\section{Objective}

Risk assessment is the process of evaluating risks to persons' safety and health from workplace hazards [1]. This data note aims to provide comprehensive information about the Health, Safety and Environment (HSE) risk assessment. Such these data sets are necessary for accident prevention and decrease the harmful impacts such as death, injuries and damages to structures and equipment at academic settings [2,3]. Also, such these risk assessment results promote information sharing across the university systems about best practices to mitigate the vulnerability of hazards [4]. Corresponding mitigation measures for each campus's highest risks is beneficial to create a University-wide relative risk ranking of all threat events and

\footnotetext{
*Correspondence: f-fatemi@alumnus.tums.ac.ir

${ }^{1}$ Research Center for Health Sciences and Technologies, Semnan

University of Medical Sciences, Semnan, Iran

Full list of author information is available at the end of the article
}

to summarize the status of campus mitigation measures [5]. Taking steps to either eliminate or to reduce risks (as far as reasonably practicable) by introducing control measures should be done in the risk management phase [6]. To achieve these goals, we developed two checklists to collect descriptive and quantitative data based on the evidence review $[7,8]$. The laboratories, public offices, and peripheral areas of the academic setting were included in this study. Besides, we planned to determine the hazard mitigation strategies for each identified hazard in the assessed areas of the academic setting in the applied checklist [9]. In the current paper, we described the collected data during the HSE risk assessment in this study. A research paper was written up and published based on our data and methodology to further describe and prioritize risks in terms of varying risk impacts in the university environment [10]. These data may help researchers to assess probability, impact, and mitigation risks in detail and find a proactive approach toward risks in higher education institutions.

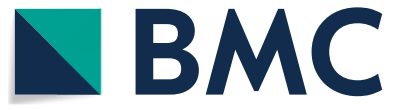

(c) The Author(s) 2020. This article is licensed under a Creative Commons Attribution 4.0 International License, which permits use, sharing, adaptation, distribution and reproduction in any medium or format, as long as you give appropriate credit to the original author(s) and the source, provide a link to the Creative Commons licence, and indicate if changes were made. The images or other third party material in this article are included in the article's Creative Commons licence, unless indicated otherwise in a credit line to the material. If material is not included in the article's Creative Commons licence and your intended use is not permitted by statutory regulation or exceeds the permitted use, you will need to obtain permission directly from the copyright holder. To view a copy of this licence, visit http://creativeco mmons.org/licenses/by/4.0/. The Creative Commons Public Domain Dedication waiver (http://creativecommons.org/publicdomain/ zero/1.0/) applies to the data made available in this article, unless otherwise stated in a credit line to the data. 
Table 1 Overview of data files

\begin{tabular}{llll}
\hline Label & Name of data file & File types (file extension) & Data repository and identifier (DOI or accession number) \\
\hline Data file 1 & Risk assessment data & Excel file (.xlsx) & https://doi.org/10.6084/m9.figshare.13106825.v1 [11] \\
Data file 2 & Analytical data & SPSS files-Variables and output (.sav) & https://doi.org/10.6084/m9.figshare.13106843.v1 [13] \\
\hline
\end{tabular}

\section{Data description}

This cross-sectional study was conducted from June to July 2018 at the School of Public Health, Semnan, University of Medical Sciences, Semnan, Iran. For implementing a successful HSE risk assessment, we needed to identify the potential hazards into three individual domains of health, safety, and environment in different areas of the academic setting. First, a list of hazards in three sections of health, safety, and environment was developed in a checklist. The reviewed literature on concerning recent accidents or incidents within universities was much helpful in defining the list of HSE hazards. The hazards checklist was completed via on-site walking and interviews by three trained students in the 39 locations of the academic setting. Additionally, the persons at risk including students, staff, or faculties were determined for each hazard in the assessed location. The descriptive analysis indicated that the most frequency of hazards was related to health hazards (50.3\%). The safety and environmental hazards were $44 \%$, and $5.7 \%$, respectively.

Second, the research team analyzed the risks based on the risk matrix in ISO 31000 [8] (see Table 1). Risk analysis was done by estimating the probability and severity of risks for identified hazards. The probability of occurrence metrics was measured on a five-point scale from "not applicable" to "inevitable". The interpretation of each scale has been mentioned in data file 1 [11]. The novelty of this study is determining the severity rate in terms of human, equipment, and institution. To estimate the effect of each identified hazard on three mentioned terms, we applied two items with a five-point score response [12]. Responses were scored and averaged to obtain an overall severity score. The severity metrics were measured on a five-point scale from "very low" to "very high". The final risk scores were calculated from multiplying probability by severity and categorized into 3 risk levels, risks rated in the top category (red) are larger than those rated in moderate category (yellow) and low category (green).

Based on the results, hazards with high risk level were belonged to safety category that they were included $5.7 \%$, required immediate mitigation measures. From all identified health, safety and environmental hazards, $6.5 \%, 36 \%$ and $43 \%$ were categorized in moderate risk level, respectively. These hazards need to be corrected in the near future. The rest of identified HSE hazards had acceptable risk score and categorized in low risk hazards. Therefore, the mitigation measures were recommended in appropriate to determined risk levels for identified hazards.

In data file 2 , in order to create a more detailed view on health, safety and environmental hazards/threats situation, the analytical tests were applied to examine associations among the main variables under study [13]. Type of analytical tests (Chi square or KruskalWallis)was used based on type of variable that is qualitative or quantitative. The most important finding is related to significant relation between the calculated risk scores and the type of hazards. The safety-related hazards indicated a statistically higher contribution to the total risk score when compared to health and environmental hazards. The descriptive analysis and providing analytical information helps to withstand and cope with the adverse effects of accidents and emergencies $[14,15]$.

\section{Limitations}

Although risk matrices can indeed be very useful in risk analysis, but can mistakenly assign higher qualitative ratings to smaller risks that leading to wrong risk management decision. It means that we might have quantitatively overestimated or underestimated the risk scores for identified hazards. Probably, applying new approaches to risk matrix such as new scaling and scoring methods to risk matrix extensions depends on the location of risk assessment in future studies would minimize the mentioned concern.

The data of this study were collected in a typical higher education institution with its exclusive hazards, which may limit its interpretation of safety, health, and environmental risks. However, the authors believe that an integrated approach for obtaining data will be beneficial to compare various domains of hazards in a workplace.

\section{Abbreviation \\ HSE: Health, safety, environment.}

\section{Acknowledgements}

We thank all colleagues and staff of the School of Public Health who supported and assisted for conducting this research. 


\section{Authors' contributions}

MJ, FA and MB collected data and contributed to entering data into dataset. FF and AD designed study, analyzed data, and prepared the manuscript. All authors read and approved the final manuscript.

\section{Funding}

There is no funding source for this research.

\section{Availability of data and materials}

The data described in this Data note can be freely and openly accessed via http://figshare.com. Please see Table 1 and Refs. $[11,13]$ for details and links to the data.

\section{Ethics approval and consent to participate}

This study was approved by the Ethics Committee Review Board at Semnan university of Medical Sciences (IR.SEMUMS.REC.1398.131). All the participants signed a consent form and were informed on the purpose of the study prior to interview as per local protocol on research ethics.

\section{Consent for publication}

Not applicable.

\section{Competing interests}

The authors declare that they have no competing interests.

\section{Author details}

${ }^{1}$ Research Center for Health Sciences and Technologies, Semnan University of Medical Sciences, Semnan, Iran. ${ }^{2}$ Student Research Committee, Semnan University of Medical Siences, Semnan, Iran.

Received: 17 October 2020 Accepted: 24 November 2020 Published online: 09 December 2020

\section{References}

1. Sarker MN, Yang B, Lv Y, Huq ME, Kamruzzaman MM. Climate change adaptation and resilience through big data. Int J Adv Comput Sci Appl. 2020;11:533-9. https://doi.org/10.14569/IJACSA.2020.0110368.

2. Farrokhi M, Khankeh $\mathrm{H}$, Poursadeqiyan $M$. The necessity to establish health, safety and environment management major at the University of Social Welfare and Rehabilitation Sciences. Health Emerg Disasters Quarterly. 2019;4(3):119-26. http://hdq.uswr.ac.ir/article-1-205-en.html.

3. Salazar-Escoboza MA, Laborin-Alvarez JF, Alvarez-Chavez CR, NoriegaOrozco L, Borbon-Morales C. Safety climate perceived by users of academic laboratories in higher education institutes. Saf Sci. 2020;121:93-9. http://www.sciencedirect.com/science/article/pii/S0925 753519306198

4. Skurka C, Quick BL, Reynolds-Tylus T, Short T, Bryan AL. An evaluation of a college campus emergency preparedness intervention. J Saf Res. 2018;65(67-72):000434745100008.

5. Yang N, Wu YM. University public emergency plan formulation: Current situation and countermeasures. Jun H, Hong C, Jianbin J, editors 2010. 40-3 p.000289654800010.

6. Marincioni F, Fraboni R. A baseline assessment of emergency planning and preparedness in Italian universities. Disasters. 2012:36(2):291-315. https://doi.org/10.1111/j.1467-7717.2011.01259.x.

7. Example risk assessments United Kingdom: Aberystwyth University; 2018 https://www.aber.ac.uk/en/hse/proc-prac/risk-assessment/\#templateand-guidance.

8. Risk management framework. Second ed: Goverment of South Australia; 2012. https://dhs.sa.gov.au/data/assets/pdf_file/0008/9782/risk-manag ement-framework.pdf.

9. Ilo PI, Izuagbe R, Mole AJC, Ekwueme L. Measuring disaster preparedness and response practices in university libraries in Nigeria: the role of disaster equipment. Int J Disaster Risk Reduct. 2018;31:85-91.

10. Dehdashti A, Fatemi F, Jannati M, Asadi F, Kangarloo MB. Applying health safety, and environmental risk assessment at academic settings. BMC Public Health; 2020. https://bmcpublichealth.biomedcentral.com/artic les/10.1186/s12889-020-09419-5.

11. Fatemi F. Risk assessment data file. figshare. Dataset. 2020. https://doi. org/10.6084/m9figshare.13106825.v1.

12. Nouri J, Mansouri N, Abbaspour M, Karbasi AR, Omidvari M. Designing a developed model for assessing the disaster induced vulnerability value in educational centers. Saf Sci. 2011;49(5):679-85. https://doi.org/10.1016/j. ssci.2011.01.002.

13. Fatemi F. Analytical data. figshare. Dataset. 2020. https://doi.org/10.6084/ m9.figshare.13106843.v1.

14. Sarker MNI, Peng Y, Yiran C, Shouse RC. Disaster resilience through big data: Way to environmental sustainability. Int J Disaster Risk Reduct. 2020;51 March:101769. https://doi.org/10.1016/j.ijdrr.2020.101769.

15. Tajdinan S, Afshari D. Checking of human errors in Ancoiler Device Control Room of Ahvaz Pipe Mill using SHERPA and HET methods at year 1390. Iran Occup Health. 2013;10(3). http://ioh.iums.ac.ir/article-1-771-en. html.

\section{Publisher's Note}

Springer Nature remains neutral with regard to jurisdictional claims in published maps and institutional affiliations.
Ready to submit your research? Choose BMC and benefit from:

- fast, convenient online submission

- thorough peer review by experienced researchers in your field

- rapid publication on acceptance

- support for research data, including large and complex data types

- gold Open Access which fosters wider collaboration and increased citations

- maximum visibility for your research: over 100M website views per year

At BMC, research is always in progress.

Learn more biomedcentral.com/submissions 